\title{
The Quaternary Glaciation of England and Wales
}

\section{By Dr. K. S. SANDFORD}

\begin{abstract}
A NUMBER of attempts have been made recently to co-ordinate the rapidly growing body of information on the Quaternary glaciation of England and Wales; and of these the most important is Prof. P. G. H. Boswell's presidential address to Section C (Geology) of the British Association at the York meeting in 1932. A report upon the subject was prepared by me for a committee of the International Geological Congress at Washington in July 1933, and the present article, based upon it, is published with the encouragement and approval of Dr. Victor Madsen (director of the Geological Survey of Denmark and organiser of the committee), and of Prof. Boswell. In preparing the report for Dr. Madsen's committee, I took Prof. Boswell's address as a standard of reference, with its writer's permission, and sought the opinions and constructive criticisms of some twenty-five authors actively engaged in Pleistocene research. Useful replies were received from twenty -one, all of whom are mentioned by name in the address. To the best of my knowledge, all literature published since the address was also taken into account and references to some of the outstanding papers are attached to these notes.

Two groups of destructive criticism should be noted : they apply equally to all attempts at correlation :-
\end{abstract}

(1) Some prominent palæontologists have stated in the past, and some continue to uphold the view, that, so far as palæontology is concerned, the evidence will not admit of more than one glacial phase in the British Isles, and that at a comparatively late date in the Pleistocene. Some botanists also support such a view. On the other hand, many members of both sciences are satisfied with the geological evidence of the alternation of glacial and interglacial episodes in this country. Even so, the warning should be repeated that the geological point of view-or that expressed by the majority of my correspondents does not meet with unqualified support, and the differences of opinion in some instances are so complete that one or the other must assuredly be wrong.

(2) Criticism of the power of archæologists to assess the culture-stages of Palæolithic implements is noticeable. Some geologists are not convinced that the opinion of the archæologist is always sound enough for him to regard groups of flint implements as infallible 'zone fossils'. If the geologist is thus led astray in these matters much of the work of correlation falls to the ground. Conversely, some geologists feel that the archæologist is inclined to be incautious in the uses he makes of geological observations and evidence. The complexity of geological relationships, particularly where land-ice is concerned, the inevitable dependence on altitudes sometimes measured with relation to datum-levels of unproved worth, the frequently thin, patchy, or discontinuous nature of the deposits, all these and other factors render the utmost caution necessary in deciphering or interpreting Pleistocene geology. In his turn the archæologist may tend to feel that the geologist is uncompromising, almost irritating, in his cautious answers to apparently simple and straightforward questions.

With these reservations duly noted, however, we seem to have gained much ground in the last few years.
There seems to be a growing belief in a four-fold glaciation of England at any rate-the Norwich Brickearth, Chalky-Jurassic Boulder Clay, Upper Chalky Drift, Brown and Hessle Boulder Clays (in part). In South Wales ${ }^{1}$, however, only two glaciations are recognised--Mousterian and Aurignacian, the former the main period of domestic ice. Earlier episodes may yet be identified there, if their deposits have not been totally destroyed or reincorporated. In the same district also the position of a raised beach (Neritoides) seems to be fixed between the two glaciations : the 'pre-glacial' (?) Patella beach is not devoid of far-travelled erratics. The Neritoides beach has been identified on the opposite side of the Bristol Channel and takes its place in an important sequence that is in accordance with the 'orthodox' views expressed in Prof. Boswell's address ${ }^{2}$.

In the north and north-east of England a number of important investigations are still in progress and it is too early to estimate their final results. In general, however, there seems to be a belief that in the Lake District, Northumberland, Durham, Yorkshire and Lincolnshire, some amplification and modification of the existing scheme will be proved on the following lines ${ }^{3}:-$ (1) Amplification of the older part of the sequence; some doubt as to the position of the Basement Clay. (2) Belief that the maximum glaciation of these districts occurred, as in other parts of England and Wales, in Upper Chalky Drift times (correlated with Upper Purple Boulder Clay and with the Mousterian culture-stage), not later. (3) Division of the Hessle Boulder Clay into an Upper and a Lower part, the lower perhaps synonymous with the Upper Purple Boulder Clay. On the east coast this is associated with the interpretation of the lateral movements of the coastal glacier passing southward from Scotland and the Cheviots. Opinions vary as to the significance of a fifth glacial incursion of parts of the area in late Upper Palæolithic times.

In the immediately adjacent counties to the south, Lincolnshire, Norfolk and Suffolk, Prof. Boswell's sequence still stands with little modification in spite of the energy of the well-qualified and vigorous investigators at work there. The position of the Cromer Till remains in discussion: the Chalky. Jurassic Boulder Clay seems to be the greatest-not the Upper Chalky Drift which predominates in the north-north-west, and in South Wales. At the Upper Palæolithic end of the sequence the Hunstanton Brown Boulder Clay is still the object of special inquiry, and a great elaboration of the beds younger than it has been set forth 4 .

In the Midlands and Upper Thames basin so far east as the Chiltern Hills, Prof. Boswell's conclusions meet with almost unqualified support ${ }^{5}$. In the Middle and Lower Thames new interpretations, based in considerable measure on archæological evidence, have been, or are about to be, published. In the Lower Thames it is now suggested that a deep channel was cut before the formation of the Taplow, 50 -foot, or Mousterian terrace ${ }^{6}$, and that that terrace is older than a Coombe Rock (associated with a cold climate).

On the whole, opinions tend to support the following :-(1) Glacial deposits older than and including 
the Chalky-Jurassic Boulder Clay fall into the Older Drift of the old classification, each separated by a hiatus of weathering and erosion. (2) The remaining glacial phases constitute the Newer Drift, of slight extent in the south but very strongly developed in the north and west? ${ }^{7}$. (3) The most marked interglacial phase followed the Older Drift. (4) In East Anglia, or parts thereof, the Chalky-Jurassic Boulder Clay (youngest member of the Older Drift) was the maximum glacial invasion: in northern England and South Wales the maximum was the Upper Chalky Drift (oldest member of the Newer Drift). The flourishing condition of British highland ice at this later episode is of particular interest.

At the present juncture few British geologists seem to be prepared to interpret the British chronology in terms of the Alpine sequence. This has been attempted on archæological evidence ${ }^{8}$, but there is a strong feeling that it is better to establish the initial sequence on its own merits, and not to introduce unnecessary complications until the second stageEuropean correlation--is attempted.

1 'T. Neville George, Geol. Mag., May 1933, pp. 208-232, and other recent contributions by the same author therein mentioned.

\& L. S. Palmer, Proc. Geol. Assoc., 42, 345, 361; 1931.

3 W. S. Bisat, Naturalist, July and October 1932: F. M. Trotter and S. E. Hollingworth, Geol. Mag., August 1932: 'A. Raistrick, and S. E. Hollingworth, Geol. Mag., August 1932: A. Raistrick, Trans. Northern Naturalists' Union, 1, Pt. 1, 1931, and Proc. Yorkshire Geol. Soc., 22, Pt. 1, November 1931. Dr. C. T. Trechmann is also taking an active part in these investigations.

J. Dolomon, Proc. Geol. Assoc, 43, 241-271; 1932. J. P. T. Burchell and J. Reid Moir, Man, February 1933.

For bibliography and correlation of this region, with specia reference to important work by Miss M. E. Tomlinson and F. W. Shotten, see some notes by the author of this review in Geol. Mag. January 1932.

6 J. P. T. Burchell and J. Reîd Moir, ibid., and Nature, May 27 1933 , p. 756 . Authorities on this district like Messrs. Chandler, Dewey, and others are still considering special problems.

$?$ This was made especially clear in Mr. E. Dixon's correspondence with the writer

8 M. C. Burkitt, Handbook of the Prehistoric and Protohistoric Sciences Congress, London, 1932. (Oxford University Press.) H. Breuil, Bull. Soc. Prehistorique Francaise, No. 12, 1932.

\section{Statistical Weather Forecasting}

$\mathrm{P}$ ROF. EMILE BOREL, the distinguished mathematician and former Minister of Marine in the French Government, gave a course of three lectures at the London School of Economics on November 14, 15 and 16, on "Quelques applications de la statistique aux previsions économiques (crises) et aux previsions meteorologiques". The first lecture, at which the French Ambassador presided, was devoted to a consideration of problems relating to the rate of interest and the devaluation of currency.

In his second and third lectures, Prof. Borel outlined a method of forecasting weather conditions. $\mathrm{He}$ first showed that, on the basis of observations at the Parc St. Maur Observatory near Paris over a period of fifty years, the greater the number of consecutive days upon which rain has fallen, the greater is the statistical probability that rain will fall on the next day. Likewise, the longer the duration of a rainless spell, the greater is the chance that the succeeding day will be rainless.

Taking the record of rainless days and of days of rain in the months October January in the fifty years, 1874-1923, Prof. Borel pointed out that rain fell on 52 per cent of the days. The probability that rain would fall on any one day between October 1 and January 31 is therefore $0 \cdot 52$. He has also tabulated the frequency of occurrence of spells of different durations of consecutive days of rain and of consecutive rainless days. The frequency of spells of one day of rain is 1,075 . The probability of rain falling on any day being 0.52 , the expected number of second successive days of rain is 559. The actual number is considerably greater, namely, 680 , corresponding to a probability of 0.63 that after a first day of rain, at least one more day of rain would occur. The probability that after two consecutive days of rain at least one more would ensue is still higher, namely, 0.66. Despite some irregularity due to insufficiency of numbers of observations, the probability that, after an $n$th day of rain, precipitation would occur on the following day, increases with the value of $n$. The irregularities disappear if the probabilities are averaged in groups of three, except for a fall in the probability curve at about the fourteenth day. Prof. Borel believes that there may possibly be a critical period in winter rainfall in Paris, in the sense that a change is more likely to occur after about fourteen consecutive days of rain than at any other time. Analysis of the frequencies of continuous spells of rainless days reveals a similar increasing probability of continuance with increasing duration, and a similar indication of a critical period at about the fourteenth day.

Examining frequencies of the number of days classified according to the quantity of rain falling during the 24 hours, Prof. Borel finds indications that the probability that, $n$ units of rain having fallen in a day, further rain would fall that day, increases with the value of $n$. He directed attention, however, to the fact that the units in which he has worked (millimetres) are arbitrary units, and different results might have been obtained if other units (say, inches) had been used.

Prof. Borel concluded by emphasising the desirability of basing further work on more abundant data than are yielded by the records of fifty years at a single meteorological station, as even this period gives small frequencies for spells of long duration and days of heavy rainfall.

F. B.

\section{Quantitative Analysis of Vegetation}

$\mathrm{S}^{\mathrm{E}}$ EVERAI, attempts have been made in recent years to apply quantitative methods to the analysis of vegetation. The present position of such investigations formed the subject of a discussion held at the Linnéan Society on November 23. The methods used may be divided into two classes : (i) those in which the object is to find a quantitative expression for the association as a whole; and (ii) those which are used to investigate the distribution of individual species within the association.

(i) Associations in Britain are conventionally described by a morphological method. The species are listed with approximate estimates of their relative abundance (dominant, frequent, rare, etc.). The variation from place to place in the association is described, and the description is illustrated by photo. 